ISSN 0103-9954

\title{
GEOPROCESSAMENTO COMO FERRAMENTA DE APOIO À GERÊNCIA DE PAVIMENTOS EM ESTRADAS FLORESTAIS
}

GEOPROCESSING AS A SUPPORT TOOL THE MANAGEMENT OF FOREST ROADS PAVEMENT

Fabiano Emmert $^{1}$ Reginaldo Sérgio Pereira ${ }^{2}$ Alba Valéria Rezende ${ }^{3}$ José Marcelo Imañas Encinas ${ }^{4}$

RESUMO

O objetivo do trabalho foi utilizar as técnicas de geoprocessamento na aquisição, manipulação, espacialização e visualização de dados do padrão de qualidade de estradas florestais, e na confecção de mapas temáticos, com a identificação de pontos críticos para o transporte de madeira, servindo como subsídio para o desenvolvimento de um programa de manutenção preventivo e regular. Identificaram-se e avaliaram-se a integridade e as condições de operação de estradas florestais mediante levantamento contínuo de defeitos na superfície de rolamento e obtenção do ICRNP (índice de condição da rodovia não-pavimentada). A base de dados georreferenciada, a alocação das unidades amostra e a espacialização da rede viária foram obtidas com auxílio da imagem do satélite CBERS II, modelo de elevação do terreno SRTM, e GPS. A identificação e a avaliação das rodovias, por meio de levantamentos detalhados em campo, demonstraram as condições da superfície de rolamento das rodovias, gerando informações sobre os trechos mais críticos e a intensidade de cada defeito, apontando ainda ações e base de custos para manutenção das estradas florestais. As técnicas de geoprocessamento, GPS, sensoriamento remoto e SIG mostraram-se como eficientes ferramentas para a interpretação, qualificação e quantificação de fenômenos naturais da região de estudo e para auxílio na gerência de pavimentos das estradas florestais. O SIG integrou os dados referentes aos padrões de operação e manutenção das rodovias à base de dados georreferenciada, manipulando, espacializando e disponibilizando visualmente, por meio de mapas, as informações geradas.

Palavras-chave: geoprocessamento; estradas florestais; gerência.

\begin{abstract}
This purpose of this research was to apply geoprocessing techniques for data acquisition, preparation, georeference, and display for assessing quality standards of forest roads and mapping critical points of the timber transportation, which contribute to support the development of a pavement preventive and ordinary maintenance program. First, the road pavement integrity and condition were assessed by conducting a continuous survey on road defects and estimating the NPRCI (Non-Paved Road Condition Index). The georeferenced dataset, the sampling unit's allocation, and the road network spatial location were conducted using satellite (CBERS-II) and SRTM imagery and GPS field data. The road identification and the assessment of pavement condition were based on a detailed field survey, which revealed the road pavement conditions and derived
\end{abstract}

1. Engenheiro Florestal, Mestrando pelo Programa de Pós-graduação em Ciências Florestais, Departamento de En genharia Florestal, Faculdade de Tecnologia, Universidade de Brasília, Caixa Postal 04357, CEP 70919-970, Brasília (DF). fabianoemmert@yahoo.com.br

2. Engenheiro Florestal, Dr., Professsor do Departamento de Engenharia Florestal, Faculdade de Tecnologia, Universidade de Brasília, Caixa Postal 04357, CEP 70919-970, Brasília (DF). reginaldosp@unb.br

3. Engenheira Florestal, Dr ${ }^{\mathrm{a}}$., Professsora do Departamento de Engenharia Florestal, Faculdade de Tecnologia, Universidade de Brasília, Caixa Postal 04357, CEP 70919-970, Brasília (DF). albavr@unb.br

4. Engenheiro Florestal, Dr., Professsor do Departamento de Engenharia Florestal, Faculdade de Tecnologia, Universidade de Brasília, Caixa Postal 04357, CEP 70919-970, Brasília (DF). imana@unb.br

Recebido para publicação em 12/03/2009 e aceito em 13/10/2009. 
useful supporting information regarding the most critical parts of the forest road and its defect severity, also pointing out practical measures to fix them, estimating costs for the required road maintenance. The Geoprocessing techniques, GPS, remote sensing dataset, and GIS showed to be efficient tools for identifying, mapping, and quantifying this natural phenomenon in the region being studied and may support the definition of maintenance program of non-paved forest roads. Results showed that the GIS could integrate the dataset containing standards of forest road ordinary operation and maintenance to a geographic database, which subsequently allowed to georeference, manipulate, and display this information on thematic maps.

Keywords: geoprocessing; forest roads; management.

\section{INTRODUÇÃO}

Desde os seus primórdios, o homem tem a necessidade de transportar matérias-primas do local de extração ou produção até o local de sua industrialização ou utilização final, favorecendo o intercâmbio e o comércio de bens e mercadorias entre povos. No Brasil, a porção mais representativa de suas instalações de transporte concentra-se no modal rodoviário com contribuição aproximada de $60 \%$ do total de toneladas transportadas por quilômetro (IBGE, 2005). Fleury (2002) atribuiu-se esse predomínio aos baixos preços praticados por esse modal, à pequena extensão e precariedade da malha ferroviária e a subutilização dos rios navegáveis.

A malha rodoviária brasileira foi estimada como sendo da ordem de 1,6 milhões de quilômetros de rodovias, dos quais apenas $196.000 \mathrm{~km}$ (12\% do total) são pavimentados. Da parcela não-pavimentada (1,4 milhões de quilômetros), 90,7\% são rodovias municipais, $8,3 \%$ estaduais e $1 \%$ federais (CNT, 2005). A relação existente entre os custos de transporte rodoviário e o padrão de qualidade de rodovias induz à necessidade de adequada e constante manutenção de rodovias convencionais e rurais, visando a evitar a sua completa deteriorização.

As principais vias de acesso às florestas são as estradas florestais, que viabilizam a implantação, a exploração e o transporte de produto florestal (MACHADO; MALINOVSKI, 1986). Com uma extensão de mais de 1 milhão de quilômetros (MACHADO; SANTOS, 1993), a rede viária florestal brasileira é indispensável nas empresas, pois, além de ser imprescindível na colheita da madeira, serve como divisão de áreas, facilitando o planejamento e o manejo florestal (SILVA; JACOVINE; VALVERDE, 2002).

Capacidade de suporte suficiente para sustentar altas cargas impostas pelo tráfego de caminhões e eficiente sistema de drenagem são requisitos mínimos para uma superfície de rolamento nessas vias de acesso. Entretanto, na maioria das vezes, o que se observa são estradas com baixo padrão construtivo, com uma estrutura básica de cascalho sobre o subleito, ou solo natural exposto sem nenhum tratamento superficial, as chamadas estradas de "terra". O motivo dessa constatação está alicerçada na grande densidade de estradas florestais observada em áreas de florestamentos, o que onera os custos de manutenção e, consequentemente, a gerência dessas vias.

Oda (1995) destacou o levantamento de campo como um fator fundamental para a análise das necessidades de manutenção e reabilitação que devem ser aplicadas à estrada, proporcionando a escolha de técnicas adequadas à solução de cada tipo de problema encontrado. Segundo Nunes (2003), a avaliação das condições de superfície de rolamento de uma estrada é feita por meio do levantamento dos defeitos no campo e para efeito de utilização de sistemas de gerência de vias, o levantamento envolve a seleção dos defeitos mais significativos, com suas respectivas medidas, avaliação da extensão e severidade de cada um.

Os defeitos causam irregularidades, provocam desconforto e, dependendo do nível de severidade, podem gerar riscos à segurança dos usuários, além de interferir na velocidade e no custo operacional do transporte rodoviário. A previsão de defeitos em estradas não pavimentadas auxilia na tomada de decisão quanto às intervenções necessárias, servindo como subsídio para o desenvolvimento de programa de manutenção preventivo e regular.

Dependendo do grau de detalhamento do estudo e das dimensões da rede viária, grande quantidade de dados é gerada, tornando-se complexa a organização e a análise desses. $\mathrm{O}$ uso de aplicativos que possibilitem organizar, armazenar, transferir e manipular esses dados podem ser ferramentas úteis na gerência de estradas.

A visualização dos dados e informações, obtidas após os levantamentos e a análise dos defeitos, aliada a utilização de técnicas que possibilitem a sua 
espacialização geográfica, torna mais fácil a compreensão dos aspectos da rede viária por parte do administrador do sistema de gerência de rodovias.

O geoprocessamento engloba diversas tecnologias de tratamento e manipulação de dados geográficos, por meio de programas computacionais. Dentre essas tecnologias, destacam-se o sensoriamento remoto, a digitalização de dados, a automação de tarefas cartográficas, a utilização de sistemas de posicionamento global (GPS) e os sistemas de informações geográficas (SIG) (SANTOS et al., 2000). Esse conjunto de tecnologias engloba vários tipos de sistemas e técnicas para tratamento da informação espacial e permite a visualização em forma de mapas, tabelas e gráficos, constituindo-se ferramenta de análise e subsídio à tomada de decisão.

Rhind (1991) mencionou que os SIG's possuem a capacidade de processamento e análise de dados espaciais, sendo definidos como equipamentos computacionais, programas e procedimentos concebidos para prover à captura, o gerenciamento, a manipulação, a análise, a modelagem e a visualização de dados espacialmente referenciados para solução de problemas complexos de planejamento. Segundo Veiga e Silva (2004), os SIG's são ferramentas que manipulam objetos (ou feições geográficas) e seus atributos (ou registros que compõem um banco de dados) por meio do seu relacionamento especial (topologia).

O objetivo do trabalho foi utilizar técnicas de geoprocessamento na coleta e análise de dados dos padrões de qualidade de estradas florestais e na confecção de mapas temáticos, identificando pontos críticos para o transporte de madeira e subsidiando o desenvolvimento de um programa de manutenção preventivo e regular.

\section{MATERIAL E MÉTODOS}

\section{Caracterização da área de estudo e do transporte florestal}

O estudo foi realizado em área de florestamento com eucalipto, pertencente à empresa mineradora Codemin, do grupo Anglo American Brasil Ltda, localizada no município de Niquelândia-GO, coordenadas $14^{\circ} 20^{\prime} 15^{\prime \prime}$ S e 48 44'27" W. A empresa utiliza a madeira em seu processo industrial. $\mathrm{O}$ solo predominante na região é o Latossolo VermelhoEscuro (LE), álico, horizonte A moderado, textura de média a arenosa, e relevo plano a suave-ondulado.

A CVC (composição veicular de carga) utilizada pela empresa era composta por veículos articulados constituídos por uma unidade tratora de tração $6 \times 2$ e um semirreboque de três eixos traseiros, com capacidade de carga média de $43 \mathrm{~m}^{3}$. O percurso dessas carretas do talhão 39 (ponto de início do trajeto) até o pátio de armazenamento de madeira na empresa possuía, aproximadamente, $100 \mathrm{~km}$, sendo $20 \mathrm{~km}$ de extensão de estradas florestais, compreendendo estradas de terra, algumas com revestimento primário (cascalho) sobre o subleito e outras sem revestimento, e $80 \mathrm{~km}$ de rodovias estaduais pavimentadas, com revestimento do tipo asfáltico.

\section{Coleta dos dados}

Foram utilizadas fontes de dados espaciais e fontes relacionadas à qualidade das estradas. Para a coleta dos dados espaciais, realizaram-se levantamentos de campos e dados de sensoriamento remoto. Convencionaram-se os dados espaciais coletados para o sistema de projeção cartográfico UTM (Projeção Universal Transversa de Mercator) e datum WGS/84.

Nos levantamentos de campo utilizou-se o aparelho receptor GPS de navegação modelo Etrex Vista da marca Garmin para aquisição das coordenadas de pontos notáveis, localizando-se cruzamentos viários, edificações, porteiras, pontes e pontos de controle. Além de pontos, foram obtidos trajetos dos deslocamentos a pé ou em um veículo de passeio ao longo da rede viária local. Os dados foram armazenados na memória digital do aparelho GPS.

Para os dados de sensoriamento remoto, foram obtidas cenas da imagem do satélite sino-brasileiro CBERS II, por meio do INPE (Instituto Nacional de Pesquisas Espaciais) e o modelo digital de elevação SRTM (Shuttle Radar Topography Mission) da Agência Nacional de Inteligência Geoespacial (National Geoespatial-Intelligence Agency - NGA) e da Administração Nacional Aeronáutica e Espacial (National Aeronautics and Space Administration NASA). A imagem do satélite CBERS II possuía formato "TIF", de órbita 158 e ponto 116, com resolução espacial de $20 \mathrm{~m}$. O modelo digital de elevação, que contemplou a área de estudo, foi a cena S15W049 de formato "HGT", com resolução espacial de $90 \mathrm{~m}$.

Os dados do padrão de qualidade das estradas florestais foram obtidos mediante inspeções, em campo, dos defeitos existentes ao longo da superfície de rolamento das estradas florestais. O trecho 
estudado correspondeu à rota de transporte partindo do talhão de n. 39, no projeto XII, do horto florestal Aranha, seguindo até o entroncamento com a rodovia estadual pavimentada GO-237.

\section{Tratamento dos dados espaciais e obtenção da base georreferenciada}

Os dados obtidos e armazenados no aparelho receptor GPS foram exportados para o programa Garmim MapSource e transformados para um arquivo de formato " $D X F$ ". Para o tratamento da imagem CBERS, utilizou-se o programa ENVI 3.5, que possibilitou a composição das bandas R4G3B2 e o corte da imagem sobre a área de estudo, gerando um arquivo "TIF".

Por meio da cena do modelo digital de elevação SRTM e do programa Global Mapper 8, foram geradas curvas de nível sobre a área de estudo com equidistância altimétrica de $10 \mathrm{~m}$, de formato " $S H P$ " (Shapefile ArcView). Em seguida, efetuaram-se os seguintes procedimentos no programa de sistema de informação geográfica ArcView 3.2:

(a) Os pontos notáveis contidos nos dados do GPS, em formato " $D X F$ ”, foram convertidos para o formato "SHP" para compor a base de dados georreferenciados;

(b) A imagem de satélite CBERS, tendo como base os dados "DXF" provenientes do GPS, foi georreferenciada com o apoio das extensões Cad Reader e Image Analysis, procedendose, em seguida, a vetorização dos elementos planimétricos da região, bem como as feições de linha para a malha viária e cursos d'água;

(c) Com a extensão 3D Analyst, foi obtida uma grade triangular do terreno ("Triangulated Irregular Network -TIN") com base nas curvas de nível interpoladas do modelo SRTM. Partindo do TIN gerado, foi possível, pela função "derive slope", obter um modelo "raster" de declividade para a região. Adotaram-se as classes de declividades de 0 a $3 \%$ para relevos planos, 3,1 a $8 \%$ suave ondulado, 8,1 a $20 \%$ ondulados, 20,1 a $45 \%$ forte ondulado, 45,1 a 75\% montanhoso e, acima de $75,1 \%$, forte montanhoso;

(d) Para a vetorização da malha viária, utilizouse o sistema topológico de arco e nó, que possibilita individualizar segmentos de retas (entre nós) de um único arquivo shape. Cada segmento, considerado como trecho rodoviário, está associado a um record (linha) da tabela de dados relacional do arquivo shape da malha viária. Essa tabela é automaticamente gerada pelo programa quando da criação de um novo tema (arquivo shape) ou feição (Linha, Ponto ou Polígono). Por meio da extensão Xtools, foram obtidos os comprimentos (m) de cada segmento de reta da malha viária, armazenando essa informação em sua tabela de dados relacional georreferenciados. O perímetro (m) e a área (ha) foram obtidos com a mesma ferramenta para poligonal da área de estudo; e

(e) De posse dos dados planimétricos, pontos notáveis e dados altimétricos (curvas de nível) foi gerada uma base de dados georreferenciada da região em formato digital "SHP".

\section{Sistema de avaliação e gerenciamento da rede viária}

A metodologia adotada para a avaliação das condições das estradas florestais seguiu as recomendações do sistema de avaliação e gerenciamento de rede viária proposta por Baesso e Gonçalves (2003), que tem por objetivo disponibilizar uma ferramenta de gerenciamento da manutenção de estradas não pavimentadas rurais, auxiliando na priorização de investimentos. Adequações foram feitas tendo em vista o cenário florestal. Seguiram-se as seguintes etapas para a aplicação da metodologia:

(a) Classificação e identificação da rede viáriaa rede viária correspondente ao trecho de estudo foi subdividida e classificada de acordo com sua funcionalidade florestal, como estrada principal, secundária ou terciária. A identificação da rede estabeleceu parâmetros de divisão em ramos, seções e unidades simples, levando-se em conta os aspectos como hierarquia funcional, dispositivos de drenagem, presença ou não de revestimentos, largura e comprimento dos segmentos. Os pontos (extremidades) de todos os segmentos de ramos, seções e unidades simples da rede viária tiveram suas coordenadas geográficas obtidas por meio do GPS;

(b) Inspeção das condições da superficie de rolamento - a inspeção foi realizada em campo, tendo como limite a área das unidades simples alocadas em uma seção 
(aproximadamente $50 \mathrm{~m}$ de comprimento $\mathrm{x}$ largura da seção em metros). Quando presentes foram observados e mensurados os defeitos seção transversal imprópria, drenagem inadequada, buracos, poeira, corrugações, perdas de agregados e trilhas de rodas. Esses defeitos foram classificados em três níveis de severidade (baixo, médio ou alto) conforme especificações pré-estabelecidas. Após a inspeção foi calculado o ICRNP (Índice de Condição da Rodovia Não Pavimentada), tendo como base os defeitos e a extensão de cada subdivisão da rede. Esse índice forneceu a medida da integridade e das condições de operação da rodovia de acordo com as seguintes classes propostas por Baesso e Gonçalves (2003): (a) Excelente $(100<$ ICRNP > 85); (b) Muito Boa (85 = ICRNP > 70); (c) Boa (70 = ICRNP > 55); (d) Regular (55 = ICRNP > 40); (e) Pobre (40 = ICRNP > 25); (f) Muito Pobre (25 = ICRNP > 10); e (g) Péssima $(10=$ ICRNP $>0)$;

(c) Determinação das prioridades de manutenção - foram estabelecidos critérios de priorização de manutenção da rodovia baseada nos valores do ICRNP e na classificação funcional. As estradas principais possuíram prioridade de manutenção na categoria funcional, seguida das secundárias e terciárias respectivamente. Para cada categoria funcional foram estabelecidas faixas de ICRNP, conforme apresentado no Tabela 1. Atribui-se o maior nível de prioridade de manutenção para o menor valor de ICRNP combinado com a maior hierarquia funcional. Trechos de estradas florestais que apresentaram valores de ICRNP abaixo da faixa estabelecida, para a sua categoria funcional, foram priorizados;

TABELA 1: Categorias funcionais e faixas de ICRNP.

TABLE 1: Functional category and band of the ICRNP.

\begin{tabular}{l|c|l}
\hline \multicolumn{2}{l|}{ Categoria Funcional } & \multirow{2}{*}{ Faix a de ICRNP } \\
\cline { 1 - 2 } Tipo & Código & \\
\hline Principal & 1 & 70,1 a 100 \\
\hline Secundária & 2 & 40,1 a 70 \\
Terciária & 3 & 10,1 a 40 \\
\hline Comprometida & 4 & 0 a 10 \\
\hline
\end{tabular}

Em que: ICRNP = Índice de Condição da Rodovia Não Pavimentada. (d) Opções de manutenção - para uma análise mais detalhada das condições da superfície de rolamento e manutenção das rodovias, foram realizadas associações entre os defeitos existentes nas secções e seus níveis de severidade. Na Tabela 2, são apresentadas para cada tipo de defeito e seus níveis de severidade, as descrições das opções de intervenção e o respectivo código do custo pertinente;

(e) Gerenciamento de dados - o cadastramento dos dados e informações sobre as rodovias foram dispostos de maneira tabular em planilhas eletrônicas do programa "Excel". Cada seção da rede viária contou com informações quanto ao enquadramento na sua funcionalidade florestal, identificação viária e valor de ICRNP, bem como a prioridade e opção de manutenção.

A categoria de estradas florestais principais representava o eixo principal de escoamento da produção madeireira, ligando os hortos florestais aos pátios de estocagem nas unidades beneficiadoras. Para o caso do horto florestal aranha, as estradas principais eram utilizadas também por usuários residentes e visitantes da região, sendo uma rodovia de jurisdição municipal. As estradas secundárias ligavam os projetos e talhões explorados à estrada principal. As terciárias se constituíam das estradas (aceiros e carreadores) divisoras dos talhões, ligando-se às estradas secundárias. As duas últimas eram utilizadas pelo transporte, equipamentos, veículos e mão-de-obra utilizados na colheita florestal.

O enquadramento das rodovias nas faixas de ICRNP foi estipulado levando-se em consideração os padrões construtivos, operacionais e defeitos de cada categoria funcional de estradas florestais. Para a determinação das prioridades de manutenção, ordenaram-se as rodovias em principais, secundárias e terciárias. Em seguida, estas foram classificadas, dentro de cada categoria funcional, do menor para o maior valor de ICRNP. Cada categoria funcional possuía uma faixa de valores de ICRNP em que deveria estar enquadrada. A orientação de priorização deveu-se, primeiramente, para as estradas com valor de ICRNP abaixo de sua faixa, em seguida, para as de valor de ICRNP contidas no intervalo de sua faixa e, por último, para as de valor de ICRNP acima de sua faixa. Escolheu-se uma rodovia por categoria funcional, repetindo-se o ciclo até que fossem determinadas todas as prioridades. 
TABELA 2: Opções de intervenção e custos pertinentes.

TABLE 2: Alternatives of intervention and pertinent costs.

\begin{tabular}{|c|c|c|c|c|c|c|}
\hline \multirow{2}{*}{ Defeito } & \multicolumn{2}{|c|}{ Severidade } & \multicolumn{2}{|r|}{ Opção de Manutenção } & \multicolumn{2}{|r|}{ Custo } \\
\hline & Nível & Código & Código & Descrição & Código & Descrição \\
\hline \multirow{3}{*}{ 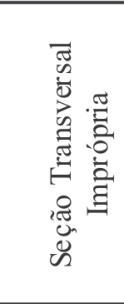 } & Baixo & 1 & st1 & Patrolamento & 2 & Pessoal + Equipamentos \\
\hline & Médio & 2 & st 2 & $\begin{array}{l}\text { Patrolamento, adição de material e } \\
\text { compactação }\end{array}$ & 3 & $\begin{array}{l}\text { Pessoal }+ \text { Equipamentos } \\
\text { ou Pessoal }+ \\
\text { Equipamentos }+ \\
\text { Material }\end{array}$ \\
\hline & Alto & 3 & st3 & $\begin{array}{l}\text { Gradeamento, adição de material, } \\
\text { umedecimento ou secagem, conformação e } \\
\text { compactação da plataforma }\end{array}$ & 4 & $\begin{array}{l}\text { Pessoal }+ \\
\text { Equipamentos }+ \\
\text { Material }\end{array}$ \\
\hline \multirow{3}{*}{ 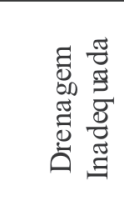 } & Baixo & 1 & $\mathrm{dr} 1$ & Limpeza de drenagem uma vez ao ano & 2 & Pessoal + Equipamentos \\
\hline & Médio & 2 & $\mathrm{dr} 2$ & Limpeza dos Bueiros & 1 & Pes soal \\
\hline & Alto & 3 & $\mathrm{dr} 3$ & $\begin{array}{l}\text { Execução de drenagem profunda, } \\
\text { redimensionamento de bueiros, uso de } \\
\text { geotexteis ou drenagem subprofundas }\end{array}$ & 4 & $\begin{array}{l}\text { Pessoal }+ \\
\text { Equipamentos }+ \\
\text { Material }\end{array}$ \\
\hline \multirow{3}{*}{ 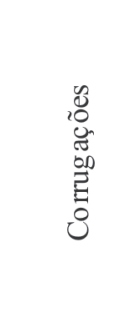 } & Baixo & 1 & cr 1 & Patrolamento & 2 & Pessoal + Equipamentos \\
\hline & Médio & 2 & $\operatorname{cr} 2$ & $\begin{array}{l}\text { Patrolamento, adição de material e } \\
\text { compactação }\end{array}$ & 3 & $\begin{array}{l}\text { Pessoal + Equipamentos } \\
\text { ou Pessoal }+ \\
\text { Equipamentos }+ \\
\text { Material }\end{array}$ \\
\hline & Alto & 3 & cr3 & $\begin{array}{l}\text { Gradeamento, adição de material, } \\
\text { umedecimento ou secagem, conformação e } \\
\text { compactação da plataforma }\end{array}$ & 4 & $\begin{array}{l}\text { Pessoal }+ \\
\text { Equipamentos }+ \\
\text { Material }\end{array}$ \\
\hline \multirow{3}{*}{$\begin{array}{l}\frac{\pi}{8} \\
0 \\
0 \\
0 \\
0 \\
0 \\
0 \\
0 \\
0 \\
x\end{array}$} & Baixo & 1 & po1 & Umedecer a pista & 4 & $\begin{array}{l}\text { Pessoal + Equipamentos } \\
+ \text { Material }\end{array}$ \\
\hline & Médio & 2 & po2 & Adicionar Estabilizadores & 4 & $\begin{array}{l}\text { Pessoal + Equipamentos } \\
+ \text { Material }\end{array}$ \\
\hline & Alto & 3 & po3 & $\begin{array}{l}\text { Adicionar estabilizadores, gradeamento da } \\
\text { pista, adição de agregados e estabilizad ores, } \\
\text { água, conformação e compactação }\end{array}$ & 4 & $\begin{array}{l}\text { Pessoal + Equipamentos } \\
+ \text { Material }\end{array}$ \\
\hline \multirow{3}{*}{ 总 } & Baixo & 1 & br1 & Patrolamento & 2 & $\begin{array}{l}\text { Pessoal + Equipamentos } \\
\text { Pessoal + Equipamentos }\end{array}$ \\
\hline & Médio & 2 & br2 & $\begin{array}{l}\text { Patrolamento, adição } \\
\text { compactação }\end{array}$ & 3 & $\begin{array}{l}\text { ou Pessoal }+ \\
\text { Equipamentos }+ \\
\text { Material }\end{array}$ \\
\hline & Alto & 3 & br3 & $\begin{array}{l}\text { Patrolamento, adição de material e } \\
\text { compactação }\end{array}$ & 4 & $\begin{array}{l}\text { Pessoal }+ \\
\text { Equipamentos }+ \\
\text { Material } \\
\end{array}$ \\
\hline \multirow{3}{*}{ 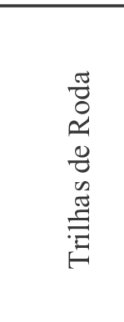 } & Baixo & 1 & $\operatorname{tr} 1$ & Patrolamento & 2 & $\begin{array}{l}\text { Pes soal + Equipamentos } \\
\text { Pessoal + Equipamentos }\end{array}$ \\
\hline & Médio & 2 & $\operatorname{tr} 2$ & $\begin{array}{l}\text { Patrolamento, adição } \\
\text { compactação de }\end{array}$ & 3 & $\begin{array}{l}\text { ou Pessoal }+ \\
\text { Equipamentos }+ \\
\text { Material } \\
\end{array}$ \\
\hline & Alto & 3 & $\operatorname{tr} 3$ & $\begin{array}{l}\text { Gradeamento, adição de material, } \\
\text { umedecimento ou secagem, conformação e } \\
\text { compactação da plataforma }\end{array}$ & 4 & $\begin{array}{l}\text { Pessoal + Equipamentos } \\
\text { + Material }\end{array}$ \\
\hline \multirow{3}{*}{ 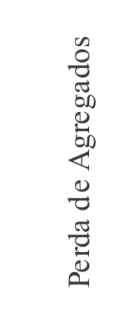 } & Baixo & 1 & pa 1 & Patrolamento & 2 & Pessoal + Equipamentos \\
\hline & Médio & 2 & pa2 & $\begin{array}{l}\text { Patrolamento, adição de material e } \\
\text { compactação }\end{array}$ & 3 & $\begin{array}{l}\text { Pessoal }+ \text { Equipamentos } \\
\text { ou Pessoal }+ \\
\text { Equipamentos }+ \\
\text { Material }\end{array}$ \\
\hline & Alto & 3 & pa3 & $\begin{array}{l}\text { Gradeamento, adição de material, } \\
\text { umedecimento ou secagem, conformação e } \\
\text { compactação da plataforma }\end{array}$ & 4 & $\begin{array}{l}\text { Pessoal }+ \\
\text { Equipamentos }+ \\
\text { Material }\end{array}$ \\
\hline
\end{tabular}


Manipulação, espacialização e visualização das informações

A manipulação, espacialização e visualização dos dados referentes aos padrões e à análise de manutenção da rede viária foram feitas por meio de um SIG, com a utilização do programa ArcView 3.2. A base de dados georreferenciada, obtida no tratamento dos dados espaciais, serviu de suporte para o relacionamento dos dados sobre as rodovias e sua localização geográfica.

Os dados referentes às rodovias avaliadas, dispostos em uma tabela, foram inseridos na tabela de dados da malha viária georreferenciada por meio da função "Join", em que cada seção (trecho rodoviário), representou uma linha da tabela. Para cada seção da malha viária georreferenciada, foram criadas colunas para a classificação funcional florestal, identificação viária, valores de ICRNP, defeitos e seus níveis de severidade. Destaca-se que a combinação "Join" ocorreu entre fontes diferenciadas de dados tabulares, havendo similaridade de uma das colunas de cada tabela e número de linhas em comum.

Utilizando-se o sistema de gerenciamento de banco de dados (SGBD) e a capacidade de cruzamento entre eles, foram obtidas as prioridades e as opções de manutenção, apresentando códigos para os custos e para as opções da intervenção a serem realizadas em cada seção da rodovia, dispostos em novas colunas da tabela de dados georreferenciada. De acordo com o código do custo e a escolha de manutenção, relacionou-se, para cada nível de severidade dos defeitos, a descrição da intervenção necessária. O valor atribuído à coluna criada para o código de custo foi o maior valor encontrado entre todos os códigos de custos de cada defeito existente na seção, representada por uma linha.

A visualização das informações geradas pelo sistema de informações geográficas foi disponibilizada por meio de tabelas e mapas temáticos. Na Figura 1, são sintetizadas todas as etapas realizadas de geoprocessamento.

\section{RESULTADOS E DISCUSSÃO}

\section{Avaliação do padrão de qualidade das estradas florestais}

Os valores de ICRNP e seus respectivos padrões de qualidade das estradas florestais são encontrados na Tabela 3. Considerando-se a maior divisão das estradas (ramo) foram observados padrões de qualidade para a estrada principal desde a categoria regular até a categoria muito boa; na classe secundária os padrões foram de pobre a muito pobre e, na terciária muito pobre. Com base nos valores de ICRNP encontrados, e seguindo as recomendações de Baesso e Gonçalves (2003), em que o ICRNP da rodovia é resultado da média ponderada do ICRNP dos ramos, pela extensão destes e da extensão total da rodovia,

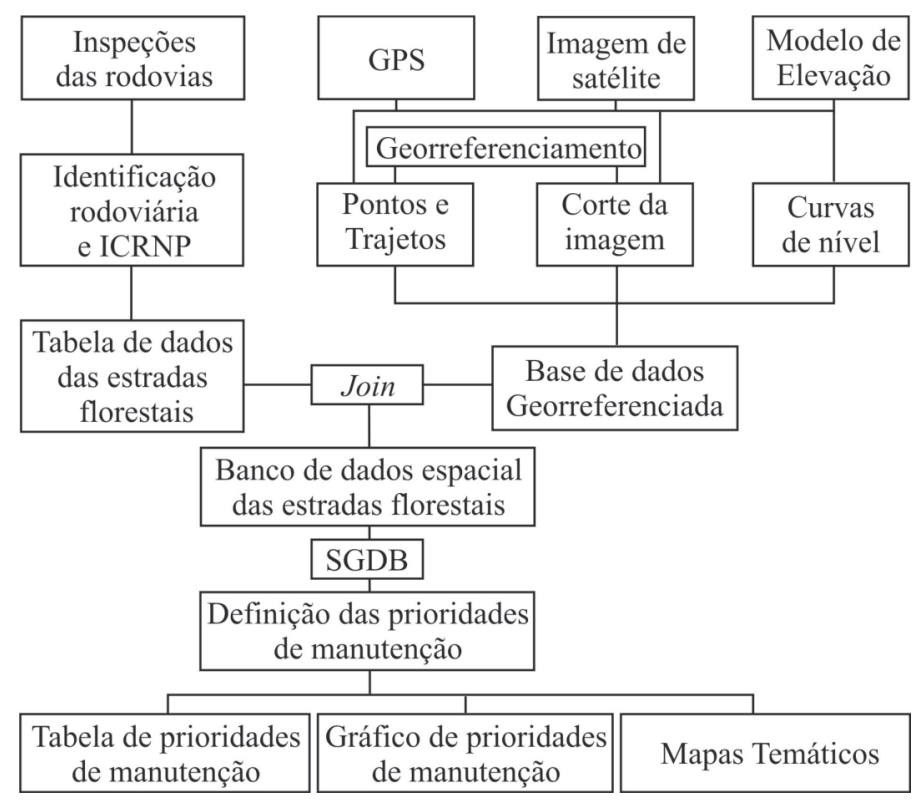

FIGURA 1: Procedimentos realizados no geoprocessamento.

FIGURE 1: Proceeding accomplished in the geographical information system. 
TABELA 3: Valores de ICRNP e padrão de qualidade das estradas florestais.

TABLE 3: Value of the ICRNP and quality standard for forest road.

\begin{tabular}{|c|c|c|c|c|c|c|c|}
\hline \multirow{2}{*}{$\begin{array}{l}\text { Categoria } \\
\text { Funcional }\end{array}$} & \multicolumn{3}{|c|}{ Identificação } & \multicolumn{4}{|c|}{ ICRNP } \\
\hline & Ramo & Seção & $\begin{array}{l}\text { Unidade } \\
\text { Simples }\end{array}$ & $\begin{array}{l}\text { Unidade } \\
\text { Simples }\end{array}$ & Seção & Ramo & Categoria \\
\hline \multirow{30}{*}{ Principal } & HAPR01 & 1 & 1 & 75,00 & 75,00 & \multirow{8}{*}{$\begin{array}{l}64,56 \\
\text { (Boa) }\end{array}$} & \multirow{21}{*}{$\begin{array}{c}57,14 \\
\text { (Regular) }\end{array}$} \\
\hline & HAPR01 & 2 & 1 & 75,00 & 75,00 & & \\
\hline & HAPR01 & 3 & 1 & 73,00 & \multirow{6}{*}{66,67} & & \\
\hline & HAPR01 & 3 & 2 & 54,00 & & & \\
\hline & HAPR01 & 3 & 3 & 39,00 & & & \\
\hline & HAPR 01 & 4 & 1 & 77,00 & & & \\
\hline & HAPR01 & 4 & 2 & 62,00 & & & \\
\hline & HAPR01 & 4 & 3 & 61,00 & & & \\
\hline & SLHAPR & 1 & 1 & 77,00 & 77,00 & \multirow{3}{*}{$\begin{array}{c}\text { 63,06 } \\
\text { (Regular) }\end{array}$} & \\
\hline & SLHAPR & 2 & 1 & 37,00 & \multirow{2}{*}{38,00} & & \\
\hline & SLHAPR & 2 & 2 & 39,00 & & & \\
\hline & SLPRA & 1 & 1 & 58,00 & \multirow{2}{*}{50,00} & \multirow{2}{*}{$\begin{array}{c}50,00 \\
\text { (Regular) }\end{array}$} & \\
\hline & SLPRA & 1 & 2 & 42,00 & & & \\
\hline & SLPRB & 1 & 1 & 77,00 & \multirow{3}{*}{70,67} & \multirow{3}{*}{$\begin{array}{c}70,67 \\
\text { (Muito Boa) }\end{array}$} & \\
\hline & SLPRB & 1 & 2 & 75,00 & & & \\
\hline & SLPRB & 1 & 3 & 60,00 & & & \\
\hline & BCPR 01 & 1 & 1 & 74,00 & 74,00 & \multirow{5}{*}{$\begin{array}{c}44,43 \\
\text { (Regular) }\end{array}$} & \\
\hline & BCPR 01 & 2 & 1 & 51,00 & 51,00 & & \\
\hline & BCPR 01 & 3 & 1 & 42,00 & \multirow{3}{*}{39,67} & & \\
\hline & BCPR 01 & 3 & 2 & 54,00 & & & \\
\hline & BCPR 01 & 3 & 3 & 23,00 & & & \\
\hline & HA1 201 & 1 & 1 & 54,00 & \multirow{7}{*}{52,43} & \multirow{10}{*}{$\begin{array}{c}42,86 \\
\text { (Pobre) }\end{array}$} & \multirow{18}{*}{$\begin{array}{c}34,10 \\
\text { (Pobre) }\end{array}$} \\
\hline & HA1 201 & 1 & 2 & 58,00 & & & \\
\hline & HA1201 & 1 & 3 & 41,00 & & & \\
\hline & HA1 201 & 1 & 4 & 55,00 & & & \\
\hline & HA1 201 & 1 & 5 & 45,00 & & & \\
\hline & HA1 201 & 1 & 6 & 69,00 & & & \\
\hline & HA1 201 & 1 & 7 & 45,00 & & & \\
\hline & HA1 201 & 2 & 1 & 18,00 & 18,00 & & \\
\hline & HA1 201 & 3 & 1 & 13,00 & \multirow{2}{*}{11,50} & & \\
\hline \multirow{12}{*}{ Secundária } & HA1 201 & 3 & 2 & 10,00 & & & \\
\hline & HA1 202 & 1 & 1 & 29,00 & \multirow{5}{*}{21,40} & & \\
\hline & HA1 202 & 1 & 2 & 19,00 & & & \\
\hline & HA1 202 & 1 & 3 & 17,00 & & & \\
\hline & HA1 202 & 1 & 4 & 20,00 & & 20,53 & \\
\hline & HA1 202 & 1 & 5 & 22,00 & & (Muito Pobre) & \\
\hline & HA1 202 & 2 & 1 & 21,00 & & & \\
\hline & HA1 202 & 2 & 2 & 23,00 & 19,67 & & \\
\hline & HA1 202 & 2 & 3 & 15,00 & & & \\
\hline & HA1 239 & 1 & 1 & 21,00 & & & \\
\hline & HA1 239 & 1 & 2 & 33,00 & 21,33 & & \\
\hline & HA1 239 & 1 & 3 & 10,00 & & & \\
\hline Terciária & HA1 239 & 2 & 1 & 17,00 & & $\begin{array}{c}23,19 \\
\text { (1) }\end{array}$ & $\begin{array}{c}23,19 \\
\text { (1) }\end{array}$ \\
\hline & HA1 239 & 2 & 2 & 30,00 & 2450 & (Muito Pobre) & (Muito Pobre) \\
\hline & HA1 239 & 2 & 3 & 30,00 & 24,50 & & \\
\hline & HA1 239 & 2 & 4 & 21,00 & & & \\
\hline
\end{tabular}

Em que: ICRNP = Índice de Condição da Rodovia Não Pavimentada. 
os valores de ICRNP encontrados foram: (a) principal - 57,14 (regular a boa); (b) secundária - 34,10 (pobre); e (c) terciária - 23,19 (muito pobre).

As estradas principais apresentavam revestimento primário de cascalho, largura de $9 \mathrm{~m} \mathrm{e}$, em geral, bom sistema de drenagem. As estradas secundárias possuíam largura entre 6 e $7 \mathrm{~m}$, alguns trechos com revestimentos de cascalhos e dispositivos de drenagem adequados, sendo que, onde não existiam revestimento, foram observados problemas com afundamento de trilhas de roda. As estradas terciárias com superfície de rolamento em leito natural, não apresentavam nenhum dispositivo de drenagem, ou se presentes, estes eram altamente comprometidos; os defeitos seção transversal imprópria e afundamento de trilha de roda foram comumente observados. A largura de faixa dessa classe de estrada era de no máximo $5 \mathrm{~m}$.

A distribuição da ocorrência de defeitos encontra-se na Figura 2. A seção 02 do ramo SLHAPR da estrada principal apresentou o menor valor de
ICRNP $(38,00)$, em que foram constatados defeitos de suporte do solo, afundamentos de trilhas de roda com nível de severidade médio, dispositivos de drenagem, seção transversal imprópria, corrugações e perdas de agregado, chegando a níveis médios de severidade conforme ilustrado na Figura 2a. Na mesma categoria funcional, observou-se que o ramo SLPRB apresentou o maior valor de ICRNP $(70,67)$ o que se justifica pela presença de revestimento de cascalho, seção transversal apropriada e drenagem adequada. Nesse mesmo ramo, a perda de agregados foi frequente, fato explicado pela colocação de cascalho no leito da estrada, espalhamento com a patrola e não compactação, o que originou um material solto que com a passagem de tráfego foi removido do centro da pista para as bordas.

O ramo em piores condições foi o HA1202 (Figura 2b), situado na estrada secundária, com ICRNP de 20,53, que apresentou altos níveis de severidade nos defeitos drenagem inadequada e perda de agregado, níveis médios de severidade em seção
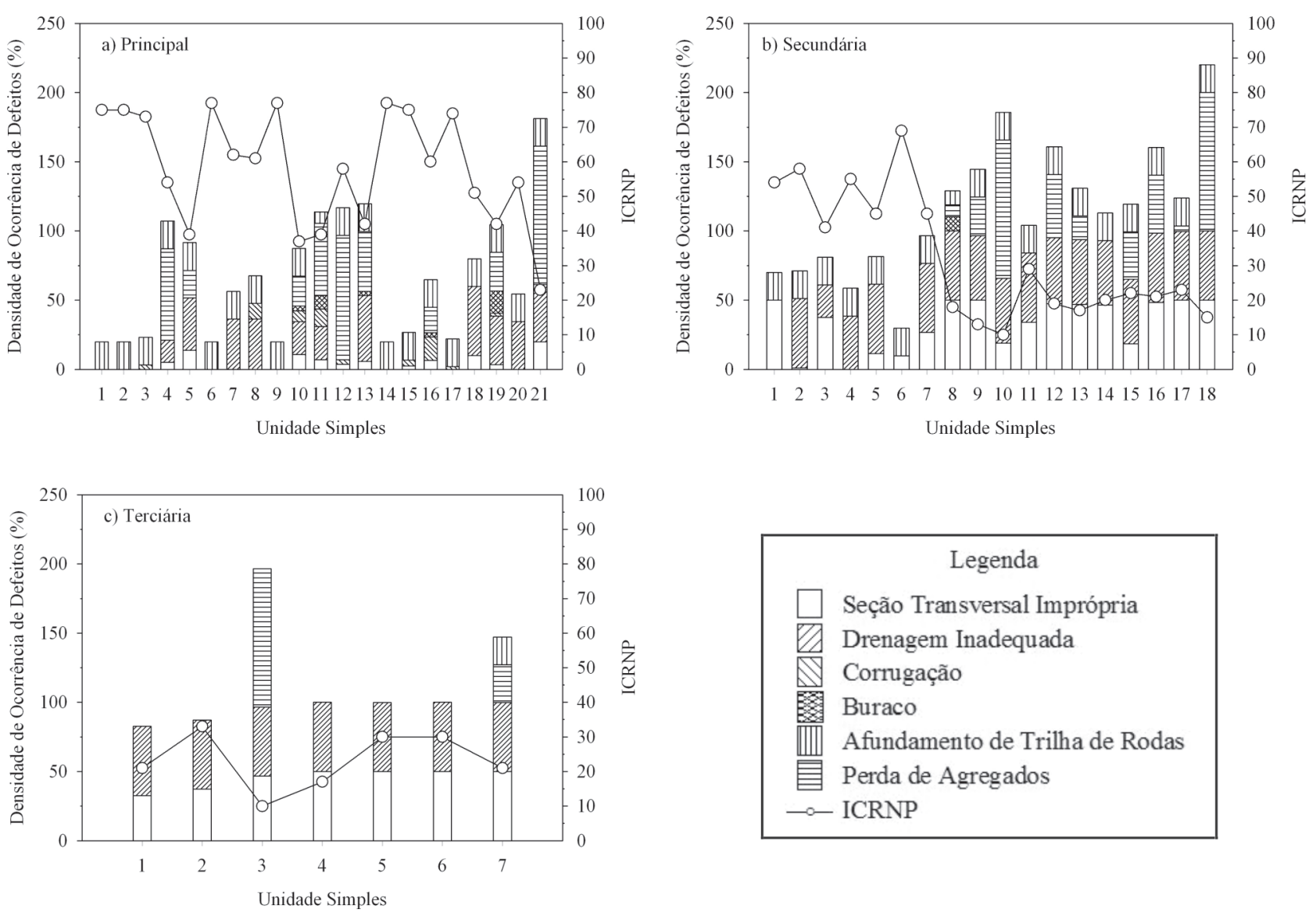

FIGURA 2: Distribuição da ocorrência de defeitos e ICRNP das unidades amostra.

FIGURE 2: Distribution for defect occurrence and ICRNP for samples unites. 
transversal imprópria e afundamento de trilhas de roda. Esse ramo não apresenta revestimento primário na superfície de rolamento. Na classe de estrada terciária, os defeitos mais evidentes foram seção transversal inadequada e drenagem inadequada (Figura 2c).

\section{Análise estatística}

Observando-se a Tabela 4, nota-se que o teste F foi significativo, ao nível de $5 \%$ de probabilidade, indicando que as classes de estradas florestais (principal, secundária e terciária) apresentam diferenças estatísticas quanto ao padrão de qualidade da pista de rolamento, obtido via análise de defeitos e determinação do ICRNP. Pelos dados apresentados no Tabela 5, de acordo com o teste Tukey, nota-se que, para as condições do trabalho, a estrada florestal classificada como principal diferiu significativamente das estradas secundária e terciária, apresentando maior valor de ICRNP e, melhor padrão de qualidade.

\section{Interação geoprocessamento e gerência de pavimentos de estradas florestais}

A base de dados georreferenciada forneceu a localização espacial de toda malha viária, cursos d'água, altimetria e pontos notáveis existentes na região da área de estudo em uma escala de 1:50.000. A malha viária georreferenciada apresentou $376 \mathrm{~km}$ de estradas não pavimentadas, a poligonal da área de reflorestamentos, 8.350.71 ha e perímetro de $54,46 \mathrm{~km}$. Aárea do talhão escolhido foi de 33,08 ha, com perímetro de $2,51 \mathrm{~km}$. O trecho da rede viária submetido à avaliação foi de $16.127 \mathrm{~m}$, sendo $12.264 \mathrm{~m}$ de estradas principais, $2.282 \mathrm{~m}$ de secundárias e $1.581 \mathrm{~m}$ de terciárias.

Em relação às classes de declividade obtidas por meio de dados altimétricos (SRTM), do total da rede viária avaliada, $26,13 \%$ do trajeto encontrou-se em relevo plano, $56,51 \%$ em suave ondulado, $16,76 \%$ em ondulado e, $0,60 \%$ em relevo forte ondulado, onde as maiores declividades situaram-se próximas aos

TABELA 4: Análise de variância do ICRNP em relação à classe das estradas florestais.

TABLE 4: Analysis of variance of the ICRNP in relation to the classroom of the forest roads.

\begin{tabular}{l|lc|r|r|r}
\hline Fonte da variação & GL & SQ & QM & F calc & F tab \\
\hline Tratamentos & 2 & 9913,415804 & 4956,708 & $18,52524 *$ & 3,21448 \\
Resíduo & 43 & 11505,30159 & 267,5652 & & \\
Total & 45 & 21418,71739 & & & \\
\hline
\end{tabular}

Em que: * significativo ao nível de 5\%; GL = graus de liberdade; $\mathrm{SQ}=$ soma de quadrados; $\mathrm{QM}=$ quadrado médio; F calc = valor de F calculado; F tab: valor de F tabelado; ICRNP = Índice de Condição da Rodovia Não Pavimentada.

TABELA 5: Média dos tratamentos, erro padrão e resultado do teste Tukey.

TABLE 5: Average of the treatments, error standard and result of the Tukey test.

\begin{tabular}{l|c|c}
\hline Classe de Estrada & Média & Erro Padrão \\
\hline 1 - Principal & $58,33 \mathrm{a}$ & 3,60 \\
2 - Secundária & $31,89 \mathrm{~b}$ & 4,30 \\
3 - Terciária & $23,14 \mathrm{~b}$ & 3,13 \\
\hline
\end{tabular}

Em que: Médias seguidas de mesma letra não diferem entre si pelo teste Tukey $(\mathrm{P}>0,05)$. 
cursos d'água transpostos pela rodovia.

De posse das coordenadas das unidades simples, foi possível realizar as segmentações topológicas em cada seção da malha viária georreferenciada, atribuindo a esses segmentos geoespaciais a localização, a identificação e os valores de defeitos em seus níveis de severidade. A Figura 3 apresenta a classificação funcional, a identificação dos ramos e seções e a sua localização na rede viária.

Os dados referentes aos defeitos da superfície de rolamento e os valores de ICRNP foram associados ao banco de dados georreferenciado da rede viária avaliada, permitindo assim, a localização geográfica e a visualização dos padrões das rodovias, conforme ilustrado na Figura 4.

Com as ferramentas de gerenciamento de dados foi possível a obtenção das prioridades de manutenção. A Figura 5 ilustra as prioridades e os itens dos custos previstos de manutenção de cada seção da rede viária avaliada. Na Figura 6, encontramse os critérios para a atribuição das prioridades. A prioridade 1 , ou seja, a maior prioridade de manutenção, foi atribuída à estrada principal na seção 02 do ramo SLHAPR, que apresentou valor mais baixo de ICRNP e inferior a faixa de valores (70 a 100) atribuída a essa categoria de estrada. A prioridade 2 correspondeu à estrada secundária na seção 03 do ramo HA1201, apresentando valor de ICRNP abaixo da faixa estabelecia (40 a 70). As estradas terciárias, compostas por duas seções apenas, apresentaram valores de ICRNP contidos em sua faixa de categoria (10 a 40) e suas prioridades de manutenção foram 13 e 15.

Ressalta-se que, o defeito "excesso de poeira" não foi considerado na análise, pois o custo para seu saneamento, independentemente do seu nível de severidade, requer os mesmos recursos (pessoal, equipamentos e materiais). Outro fator relevante é

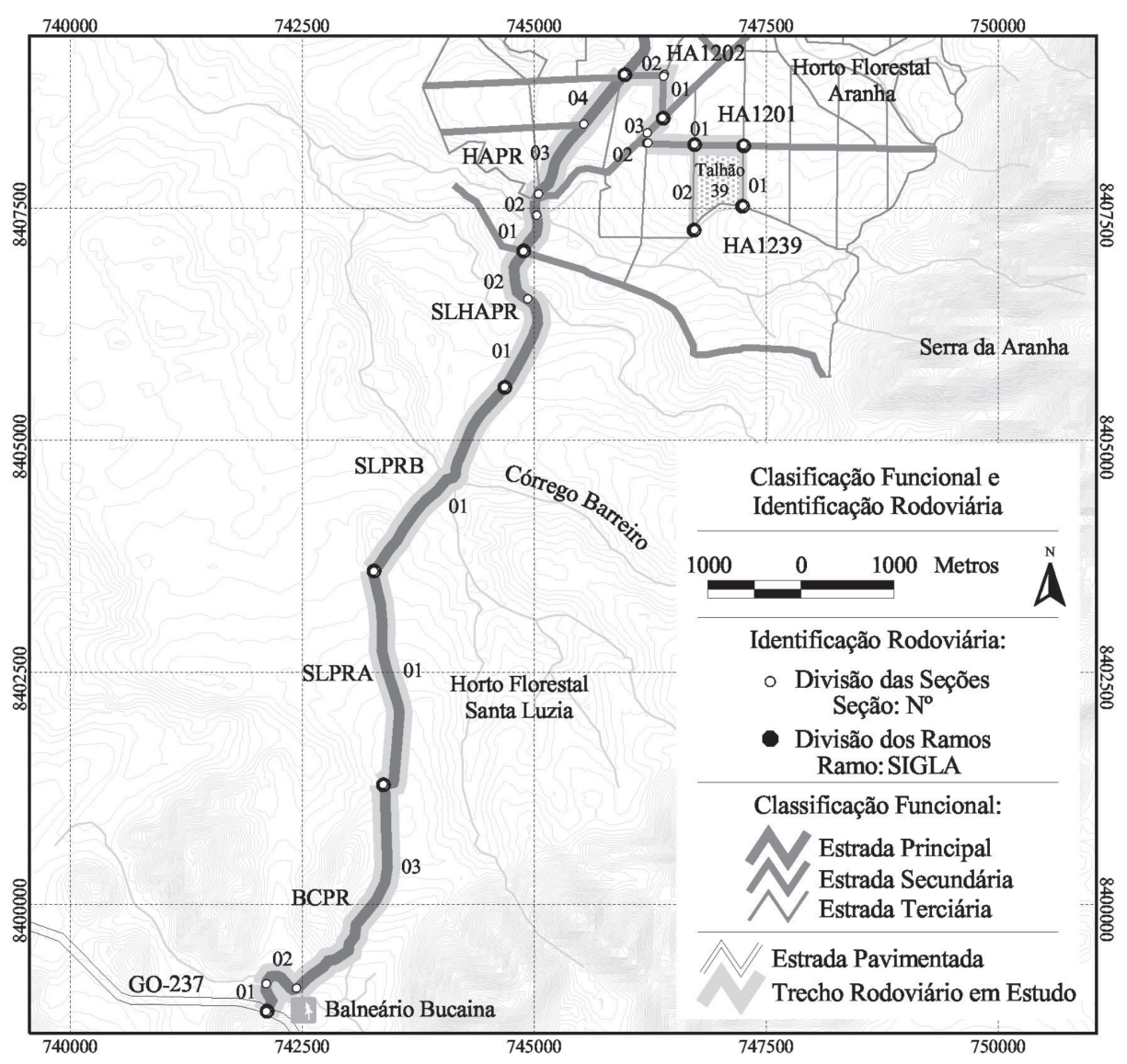

FIGURA 3: Trecho de estrada florestal avaliado, classificação funcional, ramos e seções.

FIGURE 3: Evaluated stretch of forest road, functional classification, branches and sections. 


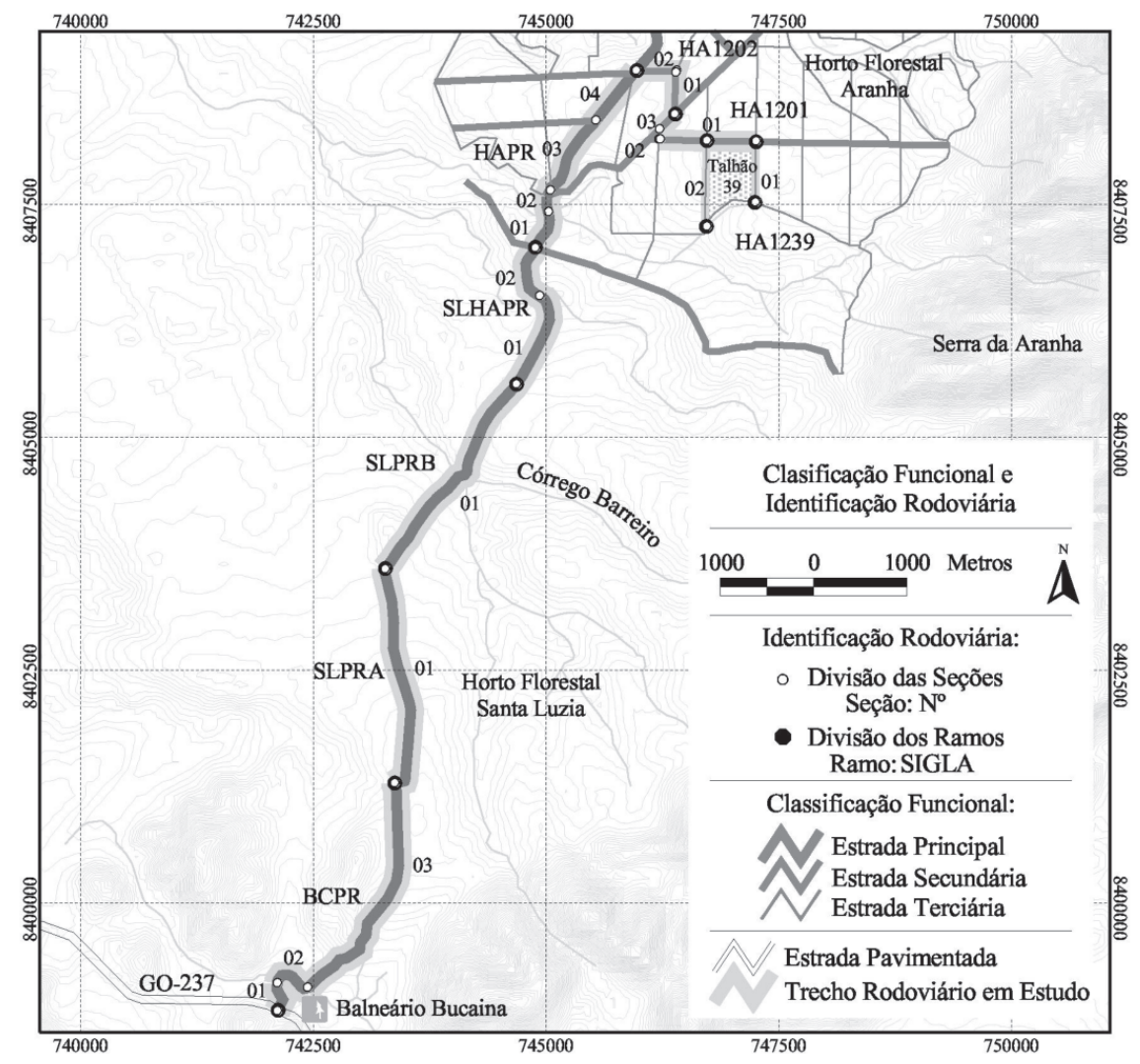

FIGURA 4: Trecho de estrada florestal avaliado e valores de ICRNP dos ramos.

FIGURE 4: Evaluated stretch of forest road and ICRNP values of the branches.

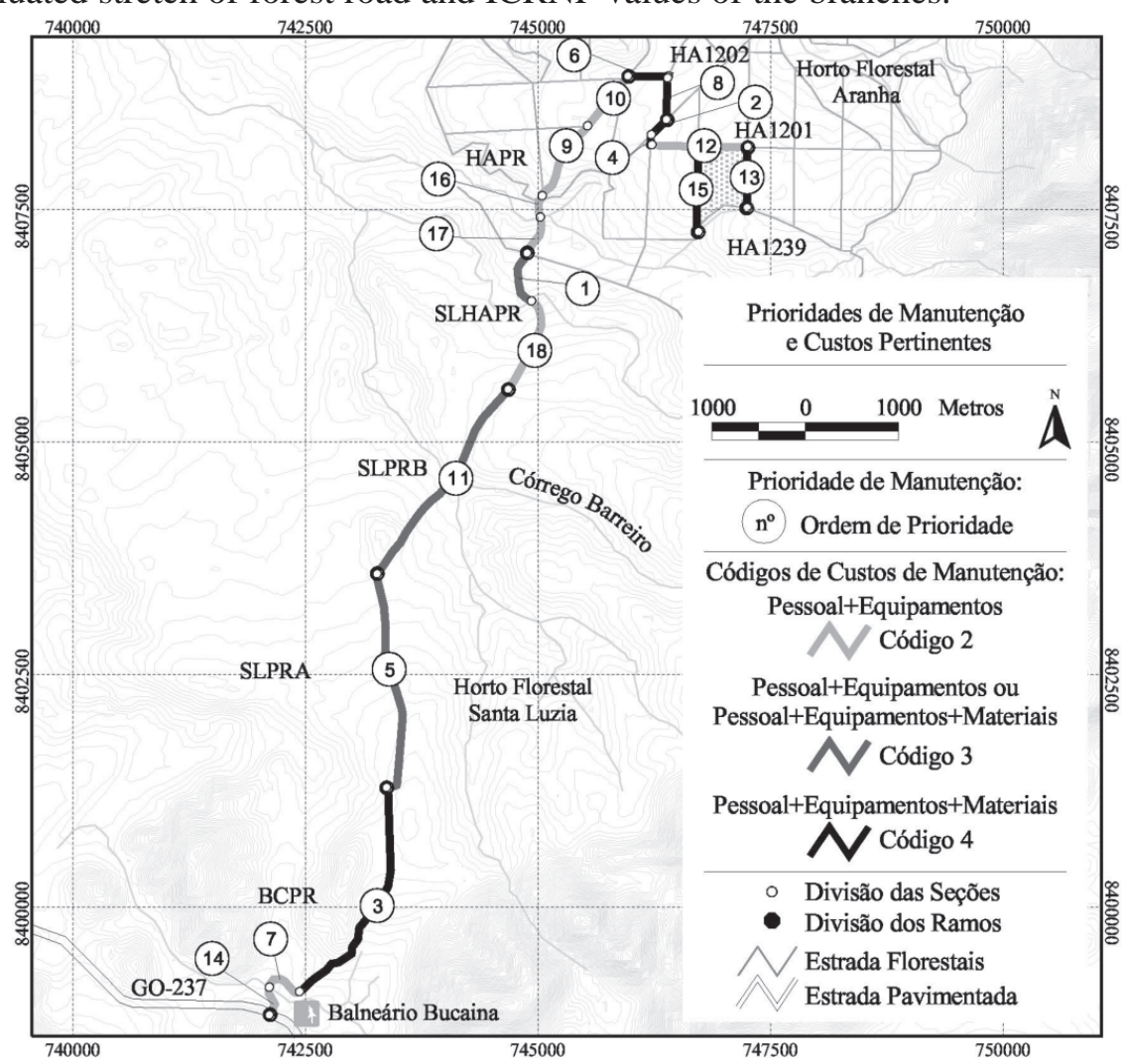

FIGURA 5: Sequência para a obtenção das prioridades de manutenção das estradas florestais:

(a) prioridades e (b) itens dos custos previstos de manutenção.

FIGURE 5: Sequence for the attainment of the priorities of maintenance of the forest roads:

(a) priorities and (b) pertinent costs of maintenance. 


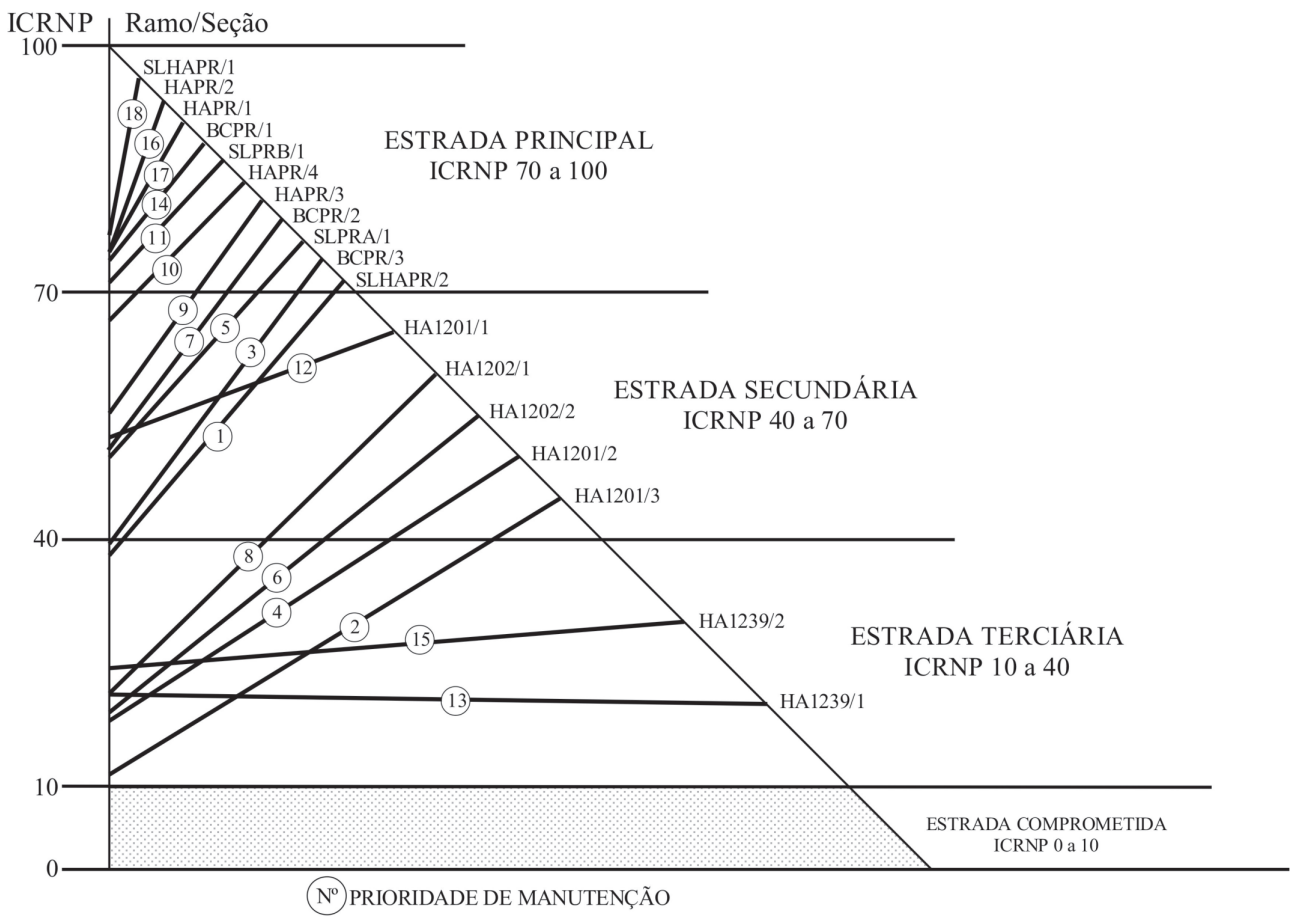

FIGURA 6: Critério para a atribuição das prioridades.

FIGURE 6: Criterion for attribution of the priorities.

atribuído ao longo período de seca, típico do clima sazonal do Cerrado, que intensifica e prolonga os efeitos da poeira dificultando intervenções.

As opções de manutenção da prioridade 1 , ou seja, a seção seção 02 do ramo SLHAPR na estrada principal, são intervenções baseadas na alocação de recursos com pessoal, equipamentos e adição de materiais. Nessa seção, entre os defeitos analisados, seção transversal imprópria foi o único que apresentou nível de severidade alto, resultando assim, no código de custo n. 4. Dessa forma, foi obtido o código da opção de manutenção, no caso "st3", que indica o gradeamento da pista, adição de material, umedecimento ou secagem do material, conformação e compactação da plataforma.

Da mesma forma, para cada seção da rede viária avaliada, consultam-se no SIG ou nas tabelas de dados das inspeções de campo os códigos e suas descrições de intervenção.

\section{CONCLUSÕES}

As seguintes conclusões foram extraídas do trabalho: (a) a identificação e a avaliação das rodovias, mediante levantamentos detalhados em campo, demonstraram as condições da superfície de rolamento destas, gerando informações sobre os trechos mais críticos e a intensidade de cada defeito, apontando ainda, ações e base de custos para manutenção das estradas florestais; (b) as técnicas de geoprocessamento, GPS, sensoriamento remoto e SIG mostraram-se como eficientes ferramentas para a interpretação, qualificação e quantificação de fenômenos naturais da região de estudo e para auxílio na gerência de pavimentos das estradas florestais; e (c) o sistema de informações geográficas integrou os dados referentes aos padrões de operação e manutenção das rodovias à base de dados georreferenciada, manipulando, espacializando e disponibilizando visualmente, através de mapas, as informações geradas.

\section{AGRADECIMENTOS}

Os autores expressam seus sinceros agradecimentos à empresa Anglo American Brasil (Codemin), pelo apoio ao desenvolvimento desta pesquisa.

\section{REFERÊNCIAS BIBLIOGRÁFICAS}

BAESSO, D. P.; GONÇALVES, F. L. R. Estradas rurais: técnicas adequadas de manutenção. Florianópolis: DER, 2003. 204 p.

CONFEDERAÇÃO NACIONAL DOS TRANSPORTES. Pesquisa rodoviária 2005: relatório gerencial. Brasília, 2005. Disponível em: < http://www.cnt.org.br>. Acesso em: 15 abr. 2006. 
FLEURY, P. F. Gestão estratégica do transporte. Revista Tecnologística, São Paulo, v. 8, n. 82, set. 2002.

INSTITUTO BRASILEIRO DE GEOGRAFIA E ESTATÍSTICA. Brasil em números/Brazil in figures. Rio de Janeiro: IBGE, 2005. v. 13.

MACHADO, C. C.; SANTOS, S. M. A rede viária florestal. In: CONGRESSO FLORESTAL PANAMERICANO, 1.; CONGRESSO FLORESTAL BRASILEIRO, 7., 1993, Curitiba. Anais... Curitiba: SBS/ SBEF, [1993]. v. 3. p. 332-336.

MACHADO, C. C.; MALINOVSKI, J. R. Rede viária florestal. Curitiba: FUPEF, 1986. 156 p.

NUNES, T. V. L. Método de previsão de defeitos em estradas vicinais de terra com base no uso das redes neurais artificiais: trecho de Aquiraz - CE. 2003. $118 \mathrm{f}$. Dissertação (Mestrado em Engenharia de Transportes) Universidade Federal do Ceará, Fortaleza, 2003.

ODA, S. Caracterização de uma rede municipal de estradas não-pavimentadas. 1995. 176 f. Dissertação (Mestrado em Engenharia de Transportes) - Escola de Engenharia de São Carlos, São Carlos, 1995.

RHIND, D. Understanding GIS the Arc/Info method. RedLands: Environment Stems Reserch Institute, 1991. $411 \mathrm{p}$

SANTOS, M. S.; PINA, M. F.; CARVALHO, M. S. (Org.). Conceitos de sistemas de informações geográficas e cartografia aplicados à saúde. Brasília: Organização Panamericana de Saúde, 2000.

SILVA, M. L.; JACOVINE, L. A. G.; VALVERDE, S. R. Economia florestal. Viçosa: UFV, 2002. 178 p.

VEIGA, T. C.; SILVA, J. X. Geprocessamento aplicado à identificação de áreas potenciais para atividades turísticas: o caso do município de Macaé-RJ. In: SILVA, J. X.; ZAIDAN, R. T. (Org.). Geoprocessamento e análise ambiental: aplicações. Rio de janeiro: Bertrand Brasil, 2004. p. 179-215. 